\title{
-
}

\section{Silencing of ADIPOQ Efficiently Suppresses Preadipocyte Differentiation in Porcine}

\author{
Yan Gao ${ }^{a, c}$ Fujuan Lia,c Yonghong Zhang ${ }^{a}$ Lisheng Daia Hao Jianga Huiyu Liu ${ }^{a}$ \\ Shumin Zhang ${ }^{\mathrm{b}}$ Chengzhen Chen $^{\mathrm{a}}$ Jiabao Zhang ${ }^{\mathrm{a}}$ \\ a'College of Animal Sciences, Jilin University, 5333 Xi'an Road, Changchun 130062, China; 'Branch of \\ Animal Husbandry, Jilin Academy of Agricultural Sciences, Gongzhuling 136100, China; 'Yan Gao and \\ Fujuan Li contributed equally to this article
}

\section{Key Words}

Pig • ADIPOQ • Preadipocytes • Adipocyte differentiation • RNAi

\begin{abstract}
Aims: Our study aims to characterize the functions of the ADIPOQ gene in the process of fat deposition of pigs, thereby providing a basis for the use of this gene as a molecular marker for pork quality. Methods: We used healthy Junmu1 piglets less than 7 days of age to establish an in vitro culture system for porcine preadipocytes. Chemically synthesized short hairpin RNAs (shRNA) were transfected into porcine preadipocytes to silence the expression of the ADIPOQ gene. We monitored preadipocyte differentiation and determined the levels of the adipocyte differentiation transcription factors lipoprotein lipase $(\mathrm{LPL})$, peroxisome proliferator-activated receptor $\gamma$ (PPAR $\gamma$ ) and adipocyte fatty acid binding protein (AP2) mRNAs to investigate the effects of ADIPOQ on the differentiation of porcine preadipocytes. Results: After transfection, the mRNA and protein levels of the ADIPOQ gene were significantly decreased $(P<0.01)$, the number of lipid droplets in the adipocytes was significantly reduced, the OD values reflecting the fat content were significantly decreased $(P<0.01)$, and the levels of LPL, PPARY and AP2 were significantly reduced $(P<0.01)$. Conclusions: These results suggest that interference with ADIPOQ gene expression can inhibit the differentiation of porcine preadipocytes.
\end{abstract}

Copyright $\odot 2013$ S. Karger AG, Basel

\section{Introduction}

In recent years, a major research goal for zoologists has been to improve livestock quality, particularly in reducing body fat deposition in livestock [1]. Therefore, studies on adipose tissue have become a focus of research. Adipose tissue is not only an energy storage 
organ but also an important endocrine organ [2]. This tissue is composed of a large number of adipocytes, which are generated through the sequential differentiation of lipoblasts to preadipocytes and immature adipocytes. Adipocyte differentiation is accompanied by changes in gene expression. The transcription factors involved in the early, middle and late stages of differentiation are LPL [3], PPAR $\gamma[4,5]$ and AP2 [6], respectively.

Adiponectin (ADIPOQ) is a collagen cytokine secreted by adipose tissue that can regulate the energy homeostasis, glucose metabolism and lipid metabolism of an organism. It is the only adipocyte-specific protein identified thus far that is negatively correlated with obesity [7]. ADIPOQ is an important in vitro signaling molecule that regulates adipocyte differentiation in adipose tissue. Expression of ADIPOQ in adipose tissue affects obesity in rodents and humans [8]. Our previous study utilized microarray technology to establish the expression profile of differentially expressed genes in the longissimus dorsi muscles of northeastern indigenous pigs and large white pigs. We demonstrated that ADIPOQ gene expression was significantly associated with fatty acid oxidation, the positive regulation of fatty acid metabolism and fatty acid $\beta$-oxidation, which play a critical role in the adipokine signaling pathway [9].

Therefore, in this study, we used healthy Junmu1 piglets less than 7 days of age as experimental animals to establish an in vitro culture system for porcine preadipocytes. Chemically synthesized shRNA were transfected into porcine preadipocytes to silence ADIPOQ expression. To investigate the effects of ADIPOQ expression on the differentiation of porcine preadipocytes, we monitored differentiation and measured the mRNA levels of adipocyte differentiation transcription factors, including LPL, PPAR $\gamma$ and AP2. Our study helps to elucidate the differentiation patterns of porcine preadipocytes, improves our understanding of adipose deposition in pigs and further reveals the function of the ADIPOQ gene in the porcine fat deposition process. Therefore, this study provides the basis for using this gene as a molecular marker for pork quality and applying this gene in early breed selection.

\section{Materials and Methods}

\section{Experimental animals}

The piglets used in this study were healthy Junmu1 piglets less than 7 days old and raised in Original Breeding Pig Farm of Jilin University (Changchun, China). Experiments were performed in accordance with the Guiding principles in the use of animals, adopted by the Chinese Association for Laboratory Animal Sciences. The study plan was approved by the Ethics Committee on the Use and Care of Animals, Jilin University.

\section{Isolation and culture of porcine preadipocytes}

The subcutaneous fat from the back of the neck was collected aseptically from piglets less than 7 days old, rinsed in phosphate buffered saline (PBS) containing 5\% double antibiotics and transferred to a glass dish to remove non-target tissues. The adipose tissue was cut into pieces approximately $1 \mathrm{~mm}^{3}$ in size using ophthalmic scissors and transferred to 50-ml centrifuge tubes, and $6 \mathrm{ml}$ of DMEM/F12 (Gibco, Beijing, China) containing $0.2 \%$ collagenase I (Sigma, Shanghai, China) was added followed by a 90 -min incubation in a $37^{\circ} \mathrm{C}$ thermostatic water bath. The digestion was terminated by adding complete culture medium, and the digested solution was filtered through 80-mesh and 200-mesh cell sieves. The filtered solution was collected and centrifuged at $1500 \mathrm{rpm}$ for $10 \mathrm{~min}$, and the supernatant was then discarded. The pellet was resuspended in $1 \mathrm{ml}$ of complete culture medium and mixed well by pipetting. This suspension was placed into a $25 \mathrm{~cm}^{2}$ cell culture flask, and $5 \mathrm{ml}$ of complete culture medium was added followed by incubation in a $37^{\circ} \mathrm{C}$ and $5 \% \mathrm{CO}_{2}$ incubator. The culture medium was changed once every 2 days, and the cells were passaged once every 3 days.

Construction of a porcine preadipocyte growth curve

The fourth generation of subcultured cells was prepared as a single-cell suspension in complete culture medium, the cell concentration was adjusted to $1 \times 10^{4}$ per $\mathrm{ml}$, and the cells were seeded in 24 -well 
culture plates in $1 \mathrm{ml}$ per well. Three wells of cells were counted every $24 \mathrm{~h}$ beginning from day 2 until the eighth group was counted. The growth curve was plotted with incubation time on the $x$-axis and the average cell number in the three wells on the $y$-axis.

\section{Transfection of porcine preadipocytes}

Each 6-well plate was seeded with $1 \times 10^{5}$ cells, and the cells were ready for transfection at $70 \%$ confluence. For transfections, $2 \mu$ l of Lipofectamine ${ }^{\mathrm{TM}} 2000$ (Invitrogen, Beijing, China) and $0.6 \mu \mathrm{g}$ of ADIPOQshRNA were each added separately to $250 \mu \mathrm{l}$ of serum-free and antibiotic-free Opti-MEM (Gibco, Beijing, China) medium. The above Lipofectamine-Opti-MEM and shRNA-Opti-MEM mixtures were gently rocked for $5 \mathrm{~min}$. The two mixtures were then combined and incubated at room temperature for $20 \mathrm{~min}$. The culture medium in the culture plates was discarded and replaced with the shRNA-Lipofectamine ${ }^{\mathrm{TM}} 2000$ mixture. The transfection was terminated by the addition of $2 \mathrm{ml}$ of complete medium $6 \mathrm{~h}$ later. For each treatment group, cell morphology was observed at $24 \mathrm{~h}, 48 \mathrm{~h}$ and $72 \mathrm{~h}$ post-transfection.

Transfection efficiency $=($ The number of fluorescent cells $\times 100 \%) \div($ The number of cells in the same visual fields).

Count randomly the number of cells in four visual fields. Calculate transfection efficiency according to formula. Compute average value. Transfection efficiency is $61 \%$.

\section{Real time PCR (RT-PCR)}

After transfection, the cells were digested with $0.25 \%$ trypsin (Gibco, Beijing, China), and total cellular RNA was extracted using TRIzol Reagent (Invitrogen, Beijing, China) at $24 \mathrm{~h}, 48 \mathrm{~h}$ and $72 \mathrm{~h}$ post-transfection. Total RNA was reverse-transcribed into cDNA using a reverse transcription kit (Takara, Dalian, China), and the resulting CDNA was used as template for RT-PCR. The sequence of the upstream primer used for RTPCR was TAT GAT GTC ACC ACT GGC AAA, and the downstream primer was TAG AGG AGC ACA GAG CCA GAG. The expected size of the amplified fragment was $185 \mathrm{bp}$. The PCR reaction system included $10 \mu \mathrm{l}$ of RealMasterMix, $0.5 \mu \mathrm{l}$ each of the upstream and downstream primers $(10 \mathrm{pmol} / \mu \mathrm{l}), 2 \mu \mathrm{l}$ of cDNA template and $7 \mu \mathrm{l}$ of $\mathrm{ddH}_{2} \mathrm{O}$. The RT-PCR conditions were as follows: $95^{\circ} \mathrm{C}$ for $2 \mathrm{~min}$ followed by 40 cycles of $95^{\circ} \mathrm{C}$ for $15 \mathrm{sec}, 60^{\circ} \mathrm{C}$ for $20 \mathrm{sec}$ and $72^{\circ} \mathrm{C}$ for $1 \mathrm{~min}$. The relative quantification method $\left(2^{-\Delta \Delta \mathrm{ct}}\right.$ method) was used to analyze the levels of ADIPOQ mRNA. Each experiment was repeated three times.

\section{Western blot analysis}

Anti-pig $\beta$-actin and anti-ADIPOQ primary antibodies were purchased from Santa Cruz Biotechnology, Inc. At $48 \mathrm{~h}$ post-transfection, the cells were digested with $0.25 \%$ trypsin, and the cellular proteins were extracted using a total protein extraction kit (BestBio, Shanghai, China). Then, $50 \mu \mathrm{g}$ of the protein samples were mixed with $5 \times$ sample loading buffer and boiled in a $105^{\circ} \mathrm{C}$ metal heat block for $10 \mathrm{~min}$, separated by electrophoresis on a $12 \%$ SDS-polyacrylamide gel and transferred to a nitrocellulose membrane with a pore size of $0.45 \mu \mathrm{m}$. The membrane was blocked in nonfat milk for $2 \mathrm{~h}$ at room temperature followed by incubation with primary antibodies against ADIPOQ and $\beta$-actin at $4{ }^{\circ} \mathrm{C}$ overnight and subsequently with peroxidase-conjugated goat anti-rabbit IgG antibodies (Boster, Wuhan, China) at room temperature for $2 \mathrm{~h}$. X-ray film was exposed using the chemiluminescence method.

\section{Induced differentiation of transfected cells}

The fourth generation of subcultured preadipocytes was seeded into 6-well plates and cultured in complete culture medium (50 ml of DMEM/F12 containing 5\% serum and 1\% double antibiotics) for one day. Differentiation medium ( $50 \mathrm{ml}$ of complete culture medium containing $15 \mathrm{mM} \mathrm{NaHCO}_{3}, 15 \mathrm{mM}$ HEPES, $33 \mu \mathrm{M}$ calcium pantothenate, $17 \mu \mathrm{M}$ transferrin and $10 \mu \mathrm{g} / \mathrm{ml}$ insulin) was added, and the time was recorded as day 0 of induction. The medium was changed every other day, and the changing pattern of lipid droplets in the cells was observed. Growth curve of porcine adipocytes after induction was constructed. The method was same as construction method of the porcine preadipocyte growth curve.

\section{Morphological observation of differentiated adipocytes}

Cells of the transfected, negative control and untransfected groups were gently rinsed with PBS three times, and the cells were fixed in 10\% neutral formalin for $30 \mathrm{~min}$. Oil Red 0 staining solution was added to sufficiently cover the bottom of the 6 -wells plates followed by $20 \mathrm{~min}$ of staining. Cells were then rinsed 


\begin{tabular}{llc}
\hline Gene & Sequence (forward / reverse) & Length (bp) \\
\hline LPL & F: GCAGGAAGTCTGACCAATAAG & 128 \\
& R: GGTTTCTGGATGCCAATAC & \\
PPAR $\gamma$ & F: ATTCGCATCTTTCAGGG & 193 \\
RP2 & F: GGACGCCATACTTTAGGA & \\
F-actin & R: GGTCTTGACTCTTCCTGTC & 186 \\
\hline
\end{tabular}

Table 1. Primers used for real-time PCR

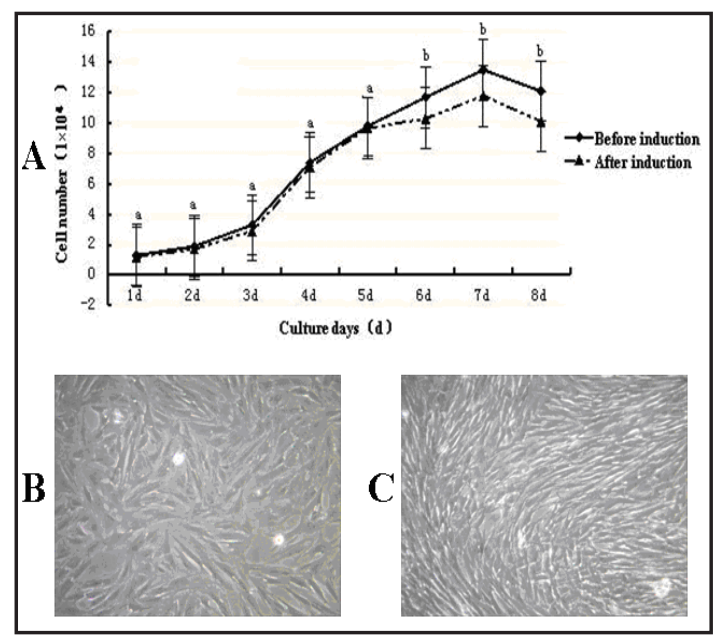

Fig. 1. Culture of porcine adipocytes. A: Growth curve of porcine adipocytes before and after induction. B: Morphology of porcine preadipocytes cultured for $24 \mathrm{~h}(100 \times)$. C: Morphology of porcine adipocytes cultured for $7 \mathrm{~d}(100 \times)$.

three times with PBS, counter-stained with hematoxylin for $15 \mathrm{~s}$, and further rinsed three times with PBS. After staining, the culture plates were placed under a light microscope for observation and imaging.

\section{Detection of biochemical indicators after adipocyte differentiation}

The cell culture plates containing the transfected, negative control and untransfected groups were fixed in 10\% neutral formalin for $30 \mathrm{~min}$, washed with PBS and stained with Oil Red 0 for $40 \mathrm{~min}$. The staining solution was removed followed by a PBS wash. The stained cells were dissolved in $1 \mathrm{ml}$ of $100 \%$ isopropanol for $15 \mathrm{~min}$, and a blank with the same treatment served as the control. The absorbance values (OD) at a wavelength of $490 \mathrm{~nm}$ were recorded using a visible spectrophotometer. Each group included three replicates.

\section{RT-PCR detection of changes in LPL, PPAR $\gamma$ and AP2 mRNA expression}

Total RNA from adipocytes transfected for $48 \mathrm{~h}$ was extracted using TRIzol. The Takara reverse transcription kit was used to reverse-transcribe the RNA. RT-PCR was performed to detect changes in the levels of the adipocyte differentiation transcription factors LPL, PPAR $\gamma$ and AP2 mRNA after transfection. The PCR primer sequences are listed in Table 1. The PCR reaction system included $10 \mu \mathrm{l}$ of RealMasterMix, $0.5 \mu \mathrm{l}$ each of the upstream and downstream primers $(10 \mathrm{pmol} / \mu \mathrm{l}), 2 \mu \mathrm{l}$ of the cDNA template, and $7 \mu \mathrm{l}$ of $\mathrm{ddH}_{2} \mathrm{O}$. The RT-PCR conditions were as follows: $95^{\circ} \mathrm{C}$ for $2 \mathrm{~min}$ and 40 cycles of $95^{\circ} \mathrm{C}$ for $15 \mathrm{sec}, 60^{\circ} \mathrm{C}$ for 20 sec and $72{ }^{\circ} \mathrm{C}$ for $1 \mathrm{~min}$. The relative quantification method ( $2^{-\Delta \Delta \mathrm{Ct}}$ method) was used to analyze the levels of LPL, PPAR $\gamma$ and AP2 mRNA. Each experiment was repeated three times.

\section{Statistical analysis}

The experimental data are expressed as the mean \pm standard deviation (SD). One-way ANOVA using SPSS16.0 was used for analysis of variance and tests of significance, and the differences between the treatment groups were compared using the Least Significant Difference test.

\section{Results}

\section{Culture of porcine adipocytes}

The growth curves of porcine adipocytes before and after induction are shown in Figure $1 \mathrm{~A}$, which are similar. The preadipocytes entered the latent phase approximately $2 \mathrm{~d}$ after 




Fig. 2. Detection of silencing effect. A: Fluorescence micrograph of porcine preadipocytes transfected for 24h, 48h, 72h with ADIPOQ-shRNA (40x). B: ADIPOQ mRNA levels in porcine preadipocytes in the different treatment groups. Data are shown as the mean \pm SD of 3 experiments. Statistical significance was determined between the blank control, negative control and transfection group. Means without a common superscript differ $(\mathrm{P}<0.01)$. C: ADIPOQ protein expression level in porcine preadipocytes after transfection with ADIPOQshRNA for $48 \mathrm{~h}(\mathrm{P}<0.01)$.

inoculation followed by a logarithmic growth phase on day 3 and a plateau phase on day 6 of culture. The number of preadipocytes peaked on day 7, with up to $13.5 \times 10^{4}$ cells. The preadipocytes entered a decline phase after $8 \mathrm{~d}$ in culture.

After $6 \mathrm{~h}$ of culture, the collagenase-digested preadipocytes began to show a small number of scattered adherent fibroblast-like cells and spherical non-adherent cells. Most of the adherent cells were short and spindle-shaped or irregular and triangular. In Figure 1B, after $24 \mathrm{~h}$ of culture, the cells showed an overlapping growth pattern when the cell density was too high. Moreover, the lack of nutrients for cells and the effects of metabolites on cell growth led to contact inhibition. Figure $1 \mathrm{C}$ shows the cells after $7 \mathrm{~d}$ of culture.

\section{Detection of silencing effect}

The ADIPOQ-shRNA containing green fluorescent protein was transfected into porcine preadipocytes. After $24 \mathrm{~h}$, successful transfection was observed as the expression of green fluorescent protein by fluorescence microscopy (Fig. 2A), whereas the un-transfected group did not show fluorescence. Green fluorescent protein expression was strongest at $48 \mathrm{~h}$ posttransfection and gradually decreased by $72 \mathrm{~h}$ post-transfection (Fig. 2A).

The relative levels of ADIPOQ mRNA at $24 \mathrm{~h}, 48 \mathrm{~h}$ and $72 \mathrm{~h}$ post-transfection were significantly lower than in the untreated and the negative control groups $(\mathrm{P}<0.01)$. No 


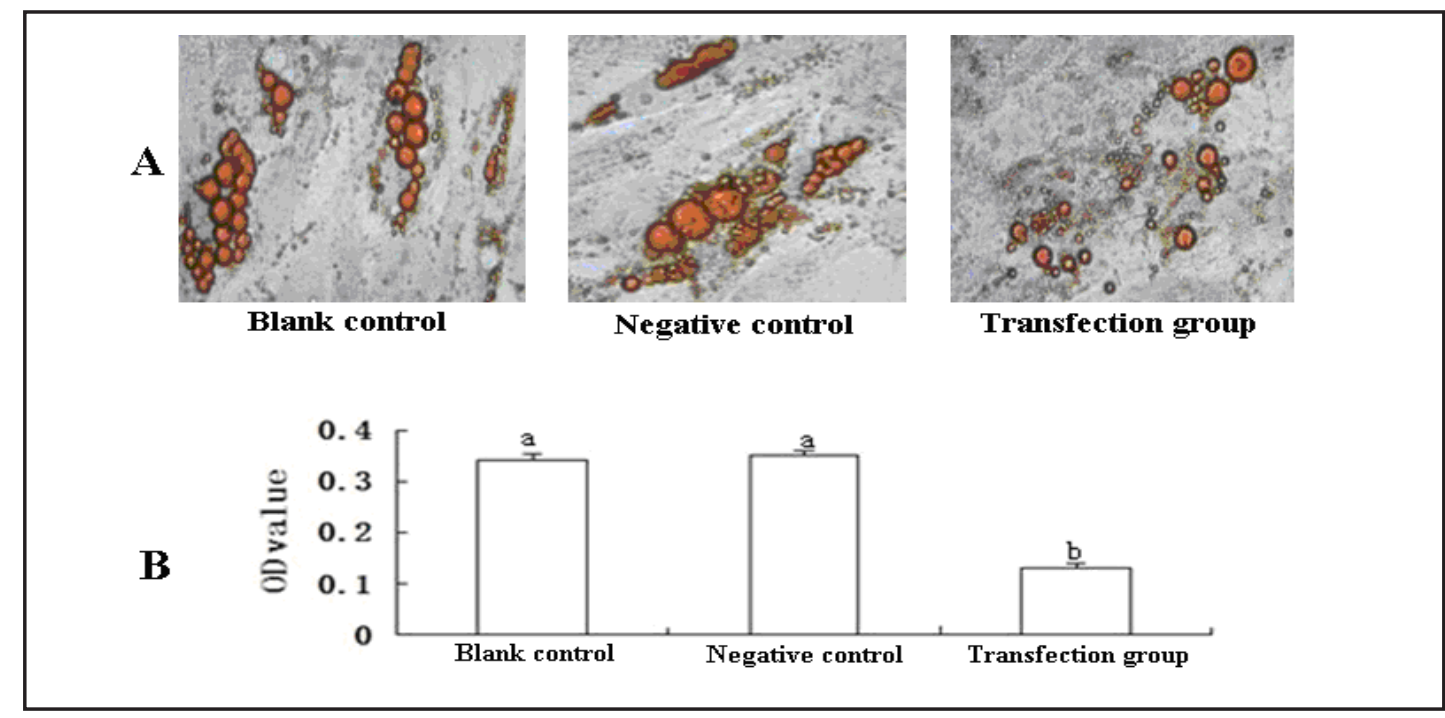

Fig. 3. Effects of ADIPOQ-shRNA on the differentiation of porcine preadipocytes. A: Morphological changes and lipid accumulation in differentiating porcine adipocytes transfected with ADIPOQ-shRNA (200x). B: Cellular lipid contents in differentiating porcine adipocytes transfected with ADIPOQ-shRNA. Data are shown as the mean \pm SD of 3 experiments. Statistical significance was determined between the blank control, negative control and transfection group. Means without a common superscript differ $(\mathrm{P}<0.01)$.

Fig. 4. $L P L, P P A R \gamma$ and AP2 mRNA levels in differentiating porcine adipocytes transfected with ADIPOQshRNA. Data are shown as the mean \pm SD of 3 experiments. Statistical significance was determined between the blank control, negative control and transfection group. Means without a common superscript differ $(\mathrm{P}<0.01)$.

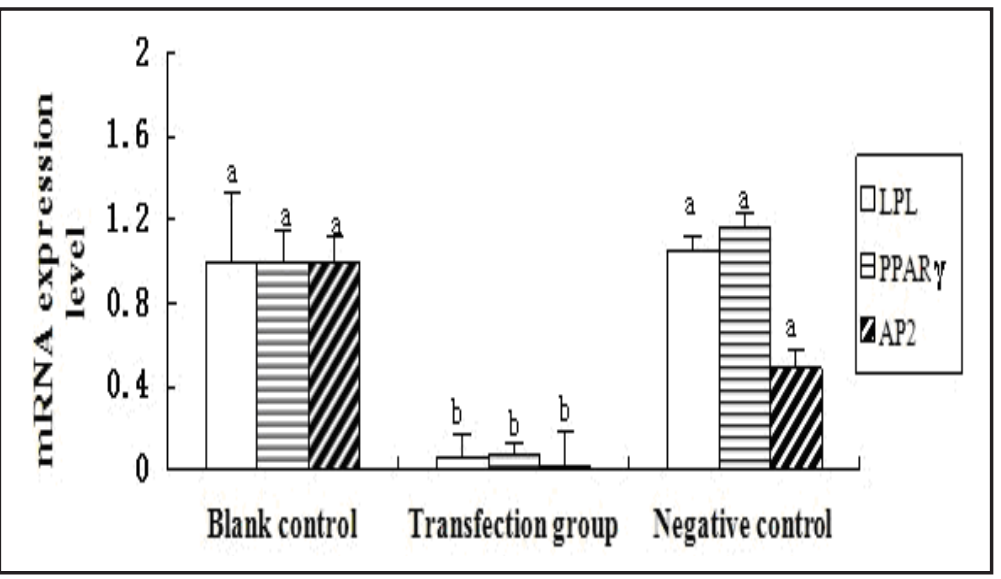

significant difference was found between the untreated and the negative control groups $(\mathrm{P}>0.05)$. The effect of ADIPOQ expression was most significant at $48 \mathrm{~h}$ post-transfection (Fig. 2B). Compared with the untransfected and the negative control groups, the expression level of the ADIPOQ protein in the preadipocytes was significantly reduced after the cells were transfected for $48 \mathrm{~h}(\mathrm{P}<0.01)$ (Fig. 2C).

\section{Effects of ADIPOQ-shRNA on the differentiation of porcine preadipocytes}

After induction of preadipocyte differentiation, the number of lipid droplets in the adipocytes was significantly reduced in the transfected group, whereas cells of the negative control and untransfected groups showed increased numbers of lipid droplets and larger droplet sizes (Fig. 3A). Oil Red O staining was used to measure the lipid content to monitor adipocyte differentiation after ADIPOQ-shRNA transfection; the results are shown in Figure $3 \mathrm{~B}$. The OD value of adipocytes in the transfected group was significantly reduced $(\mathrm{P}<0.01)$, 
whereas the OD values of the untransfected and the negative control groups did not show significant changes $(P>0.05)$. These results suggest that the lipid content of adipocytes in the transfected group was significantly reduced.

Changes in the mRNA levels of adipocyte differentiation transcription factors after transfection

RT-PCR results showed that the mRNA levels of the adipocyte differentiation transcription factors LPL, PPAR $\gamma$ and AP2 changed. Compared with the untreated and the negative control groups, the LPL, PPAR $\gamma$ and AP2 mRNA levels in the transfected group were significantly reduced $(\mathrm{P}<0.01)$, whereas the untreated and the negative control groups did not show significant differences $(\mathrm{P}>0.05)$ (Fig. 4).

\section{Discussion}

The growth curve of cells is an important manifestation of the basic patterns of cell growth. In this study, porcine preadipocytes proliferated exponentially beginning from day 3 of in vitro culture. The rate of proliferation began to decrease and entered the plateau phase of cell growth on day 6. Cell numbers peaked on day 7, and the total number of cells declined on day 8 upon entering the decline phase (Fig. 1A). The growth curve was approximately S-shaped, consistent with standard cell growth and proliferation patterns. This study found that small lipid droplets also appeared in preadipocytes in the absence of differentiationinducing agents after culturing preadipocytes for $7 \mathrm{~d}$, which is consistent with reports by Akambi et al. [10] and Ding et al. [11].

ADIPOQ is the most abundant protein secreted by white adipose tissue. It is closely associated with fat metabolism and involved in the regulation of adipose tissue deposition [12]. Its secretion negatively correlates with adipose tissue deposition [13, 14]. A previous study by Yamauchi et al. showed the relationship between ADIPOQ and AMPK revealed that ADIPOQ functions by promoting the phosphorylation of acetyl coenzyme A carboxylase, fatty acid oxidation and glucose uptake and reducing gluconeogenesis in the liver and glucose levels in the body [15]. Combs et al. found that ADIPOQ could reduce the production of glucose by reducing the activity of glucose-6-phosphatase while significantly increasing the level of hepatic glucose phosphorylation in mouse models [16]. Moreover, ADIPOQ can enter the cerebrospinal fluid from the blood to act on neurons, thereby increasing glucose metabolism and reduce animal body weight[17]. Fruebis et al. found that the injection of low doses of ADIPOQ in mice can reduce the body weight of obese mice on a high sucrose diet without reducing food intake but increasing fatty acid oxidation, thereby regulating the body's energy balance [18].

In the present study, we confirmed that interfering with the expression of ADIPOQ suppresses the differentiation of preadipocytes and reduces lipid accumulation, which is consistent with the result of Yuchang Fu et al. [19] and Combs et al. [20]. Yuchang Fu et al. demonstrated that overexpression of ADIPOQ can enhance 3T3-L1 fibroblast proliferation, accelerate adipocyte differentiation, and infully differentiated adipocytes, augment lipid accumulation[19]. Combs et al. demonstrated that the overexpression of ADIPOQ can enhance the proliferation, differentiation and lipid accumulation of 3T3-L1 cells [20]. However, Bauche et al. [21] found ADIPOQ overexpression impaired adipocyte differentiation and less lipid accumulation. Why Bauche et al. indicate different result? Firstly, Bauche's result and our result are obtained from the study in vivo and in vitro, respectively, which may result in different and even contradict conclusion. Adipocyte culturing process in vitro lacks regulatory mechanism of internal environment in the process of study in vivo. Secondly, continuing stimulus of inducer contributes to the discrepancy. Finally, ADIPOQ acts locally at the tissue level to maintain adipocyte size and mass around an equilibrium set point [19]. ADIPOQ functions as an adipocyte differentiation factor[19]. The viewpoint could support our conclusion. 
ShRNA is a type of double-stranded RNA that most closely resembles naturally occurring double-stranded RNA. ShRNAs are not easily degraded, and it is simple to transfect cells directly with synthetic shRNA in a quantitative manner [22]. Fluorescent shRNA has proven to be an effective approach for monitoring transfection efficiency and optimizing transfection methods. To confirm the specificity of the shRNA, we transfected cells with a randomly synthesized negative control shRNA without any antisense sequence. The negative control shRNA did not inhibit adipocyte differentiation. In this study, we investigated the function of ADIPOQ in adipocyte differentiation by transfecting target-specific shRNA. Our results show that the shRNA method can effectively block the expression of the ADIPOQ gene in porcine preadipocytes (Fig. 2). Western blot analysis shows that although ADIPOQ protein expression was significantly decreased, expression persisted (Fig. 2C), suggesting that ADIPOQ-shRNA could not completely suppress ADIPOQ gene expression. This phenomenon may be explained by shRNA transfection efficiency and the presence of other critical factors in the lipogenesis pathway, such as EBF-1 [23]. Porcine preadipocytes have a certain degree of differentiation potential and the ability to spontaneously differentiate into mature adipocytes when grown to confluency. In this study, we successfully induced the in vitro differentiation of preadipocytes into mature adipocytes. The results of the morphological and the OD value studies (Fig. 3) confirm that ADIPOQ-shRNA inhibited adipocyte differentiation, suggesting that porcine preadipocytes can be used as a model to study the in vitro differentiation of adipocytes.

LPL is an important factor for regulating lipid accumulation and lipid mobilization. In in vitro cultures of adipocytes, LPL is expressed early during the differentiation of the cell [24]. Oku et al. (2006) demonstrated a similar expression pattern of the LPL gene during differentiation of stromal vascular cells to mature adipocytes in red snapper and during differentiation of preadipocytes cultured in vitro to mature adipocytes [25]. LPL expression begins early in lipogenesis. Moreover, LPL mRNA levels increase during the differentiation processes[26]. Therefore, when the transcription factor ADIPOQ is inhibited, the expression level of the early differentiation factor LPL is also reduced (Fig. 4). PPAR $\gamma$ plays an important role in adipocyte differentiation [27-29] and can initiate the expression of adipose tissue-specific genes [30]. Studies of impaired lipogenesis have demonstrated that PPAR $\gamma$ can promote lipid accumulation in adipocytes. During adipocyte differentiation, the PPAR $\gamma$ gene is induced and expressed earlier than most of the adipocyte-specific genes [31], and the expression of this gene stimulates preadipocytes to differentiate into mature adipocytes. Hosono et al. [32] and Xu et al. [33] used adenovirus vector-mediated RNAi and siRNA to silence the expression of PPAR $\gamma$ and found that the differentiation of the 3T3-L1 preadipocytes and human preadipocytes was inhibited $[32,33]$. It has been shown that AP2 is also one of the key genes involved in adipocyte differentiation and is highly expressed in the late stages of adipocyte differentiation [34]. In the present study, we found that after transfection of ADIPOQ-shRNA, the expression of PPAR $\gamma$ and AP2 was reduced (Fig. 4) and adipocyte differentiation was inhibited.

In this study, we used RNA interference of ADIPOQ mRNA expression, leading to a significant reduction in the mRNA levels of adipocyte differentiation transcription factors, thereby affecting the differentiation of preadipocytes into mature adipocytes. Therefore, ADIPOQ is an important and indispensable regulator of adipocyte differentiation.

\section{Abbreviations}

shRNA (short hairpin RNAs); LPL (lipoprotein lipase); PPAR $\gamma$ (peroxisome proliferatoractivated receptor $\gamma$ ); AP2 (adipocyte fatty acid binding protein); ADIPOQ (Adiponectin); PBS (phosphate buffered saline); RT-PCR (Real time PCR); SD (standard deviation). 


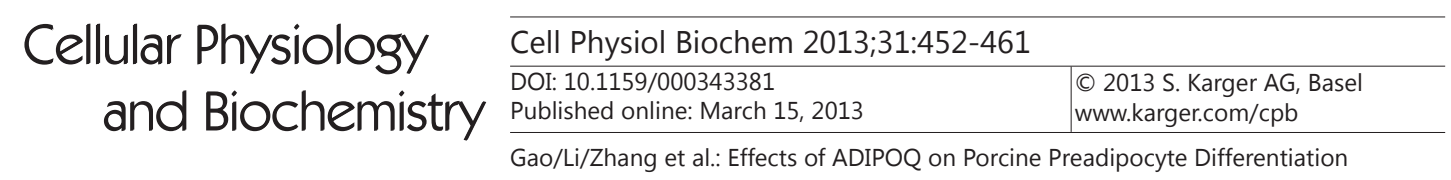

\section{Acknowledgements}

Research was supported by the Tackle Key Problems in Science and Technology Program from Jilin Province (09ZDGG008). The authors thank Boxing Sun for the maintenance and care of the animals used in this research.

\section{References}

1 Novakofski J: Adipogenesis: usefulness of in vitro and in vivo experimental models. J Anim Sci 2004;82:905-915.

2 Matsuzawa Y: Adipocytokines and metabolic syndrome. Semin Vasc Med 2005;5:34-39.

- 3 Ailhaud G: Extracellular factors, signalling pathways and differentiation of adipose precursor cells. Curr Opin Cell Biol 1990;2:1043-1049.

-4 Smith SB, Mersmann HJ, Smith EO, Britain KG: Stearoyl-coenzyme A desaturase gene expression during growth in adipose tissue from obese and crossbred pigs. J Anim Sci 1999;77:1710-1716.

-5 Kawada T, Kamei Y, Fujita A, Hida Y, Takahashi N, Sugimoto E, Fushiki T: Carotenoids and retinoids as suppressors on adipocyte differentiation via nuclear receptors. Biofactors 2000;13:103-109.

6 Dani C, Doglio A, Amri EZ, Bardon S, Fort P, Bertrand B, Grimaldi P, Ailhaud G: Cloning and regulation of a mRNA specifically expressed in the preadipose state. J Biol Chem 1989;264:10119-10125.

7 Takahashi M, Arita Y, Yamagata K, Matsukawa Y, Okutomi K, Horie M, Shimomura I, Hotta K, Kuriyama H, Kihara S, Nakamura T, Yamashita S, Funahashi T, Matsuzawa Y: Genomic structrue and mutations in adipose-specific gene, adiponectin. Int J Obes Relat Metab Disord 2000;24:861-868.

8 Hu E, Liang P, Spiegelman BM: ADIPOQ is a novel adipose specific gene dysregulated in obesity. J Biol Chem 1996;271:10697-10703.

-9 Gao Y, Zhang YH, Jiang H, Xiao SQ, Wang S, Ma Q, Sun GJ, Li FJ, Deng Q, Dai LS, Zhao ZH, Cui XS, Zhang SM, Liu DF, Zhang JB: Detection of differentially expressed genes in the longissimus dorsi of Northeastern Indigenous and Large White pigs. Genet Mol Res 2011;10:779-791.

10 Akanbi KA, Brodie AE, Suryawan A, Hu CY: Effect of age on the differentiation of porcine adipose stromalvascular cells in culture. J Anim Sci 1994;72:2828-2835.

11 Ding ST, McNeel RL, Mersmann HJ: Expression of porcine adipocyte transcripts: tissue distribution and differentiation in vitro and in vivo. Comp Biochem Physiol B Biochem Mol Biol 1999;123:307-318.

12 Fu Y, Luo N, Klein RL, Garvey WT: Adiponectin promotes adipocyte differentiation, insulin sensitivity, and lipid accumulation. J Lipid Res 2005;46:1369-1379.

13 Kadowaki T, Yamauchi T: Adiponectin and adiponectin receptors. Endocr Rev 2005;26:439-451.

14 Kadowaki T, Yamauchi T, Kubota N, Hara K, Ueki K: Adiponectin and adiponectin receptors in obesitylinked insulin resistance. Novartis Found Symp 2007;286:164-176; discussion 176-182, 200-203.

- 15 Yamauchi T, Kamon J, Minokoshi Y, Ito Y, Waki H, Uchida S, Yamashita S, Noda M, Kita S, Ueki K, Eto K, Akanuma Y, Froguel P, Foufelle F, Ferre P, Carling D, Kimura S, Nagai R, Kahn BB, Kadowaki T: Adiponectin stimulates glucose utilization and fatty-acid oxidation by activating AMP-activated protein kinase. Nat Med 2002;8:1288-1295.

16 Combs TP, Berg AH, Obici S, Scherer PE, Rossetti L: Endogenous glucose production is inhibited by the adipose-derived protein Acrp30. J Clin Invest 2001;108:1875-1881.

17 Qi Y, Takahashi N, Hileman SM, Patel HR, Berg AH, Pajvani UB, Scherer PE, Ahima RS: Adiponectin acts in the brain to decrease body weight. Nat Med 2004;10:524-529.

18 Fruebis J, Tsao TS, Javorschi S, Ebbets-Reed D, Erickson MR, Yen FT, Bihain BE, Lodish HF: Proteolytic cleavage product of 30-kDa adipocyte complement-related protein increases fatty acid oxidation in muscle and causes weight loss in mice. Proc Natl Acad Sci U S A 2001;98:2005-2010.

19 Fu Y, Luo N, Klein RL, Garvey WT: Adiponectin promotes adipocyte differentiation, insulin sensitivity, and lipid accumulation. J Lipid Res 2005;46:1369-1379. 


\section{Cellular Physiology $\quad$ Cell Physiol Biochem 2013;31:452-461 and Biochemistry \\ Gao/Li/Zhang et al.: Effects of ADIPOQ on Porcine Preadipocyte Differentiation}

20 Combs TP, Pajvani UB, Berg AH, Lin Y, Jelicks LA, Laplante M, Nawrocki AR, Rajala MW, Parlow AF, Cheeseboro L, Ding YY, Russell RG, Lindemann D, Hartley A, Baker GR, Obici S, Deshaies Y, Ludgate M, Rossetti L, Scherer PE: A transgenic mouse with a deletion in the collagenous domain of adiponectin displays elevated circulating adiponectin and improved insulin sensitivity. Endocrinology 2004;145:367383.

21 Bauche IB, El Mkadem SA, Pottier AM, Senou M, Many MC, Rezsohazy R, Penicaud L, Maeda N, Funahashi T, Brichard SM: Overexpression of adiponectin targeted to adipose tissue in transgenic mice: impaired adipocyte differentiation. Endocrinology 2007;148:1539-1549.

-22 Paddison PJ, Caudy AA, Bernstein E, Hannon GJ, Conklin DS: Short hairpin RNAs (shRNAs) induce sequence-specific silencing in mammalian cells. Genes Dev 2002;16:948-958.

-23 Akerblad P, Månsson R, Lagergren A, Westerlund S, Basta B, Lind U, Thelin A, Gisler R, Liberg D, Nelander S, Bamberg K, Sigvardsson M: Gene expression analysis suggests that EBF-1 and PPARgamma2 induce adipogenesis of NIH-3T3 cells with similar efficiency and kinetics. Physiol Genomics 2005;23:206-216.

24 Boone C, Grégoire F, Remacle C: Culture of porcine stromal-vascular cells in serum-free medium: differential action of various hormonal agents on adipose conversion. J Anim Sci 2000;78:885-895.

25 Oku H, Tokuda M, Okumura T, Umino T: Effects of insulin, triiodothyronine and fat soluble vitamins on adipocyte differentiation and LPL gene expression in the stromal-vascular cells of red sea bream, Pagrus major. Comp Biochem Physiol B Biochem Mol Biol 2006;144:326-333.

26 Boone C, Mourot J, Grégoire F, Remacle C: The adipose conversion process: regulation extracellular and intracellular factors. Reprod Nutr Dev 2000;40:325-358.

27 Tontonoz P, Nagy L, Alvarez JG, Thomazy VA, Evans RM: PPARgamma promotes monocyte/macrophage differentiation and uptake of oxidized LDL. Cell 1998;93:241-252.

28 Chawla A, Schwarz EJ, Dimaculangan DD, Lazar MA: Peroxisome proliferator-activated receptor (PPAR) gamma: adipose-predominant expression and induction early in adipocyte differentiation. Endocrinology 1994;135:798-800.

29 Tontonoz P, Hu E, Spiegelman BM: Regulation of adipocyte gene expression and differentiation by peroxisome proliferator activated receptor gamma. Curr Opin Genet Dev 1995;5:571-576.

-30 Gregoire FM, Smas CM, Sul HS: Understanding adipocyte differentiation. Physiol Rev 1998;78:783-809.

- 31 El-Jack AK, Hamm JK, Pilch PF, Farmer SR: Reconstitution of insulin-sensitive glucose transport in fibroblasts requires expression of both PPAR $\gamma$ and $C / E B P \alpha$. J Biol Chem 1999;274:7946-7951.

- 32 Hosono T, Mizuguchi H, Katayama K, Koizumi N, Kawabata K, Yamaguchi T, Nakagawa S, Watanabe Y, Mayumi T, Hayakawa T: RNA interference of PPARgamma using fiber-modified adenovirus vector efficiently suppresses preadipocyte-to-adipocyte differentiation in 3T3-L1 cells. Gene 2005;348:157-165.

-33 Xu Y, Mirmalek-Sani SH, Yang X, Zhang J, Oreffo RO: The use of small interfering RNAs to inhibit adipocyte differentiation in human preadipocytes and fetal-femur-derived mesenchymal cells. Exp Cell Res 2006;312:1856-1864.

-34 Tang QQ, Zhang JW, Daniel Lane M: Sequential gene promoter interactions of C/EBPbeta, C/EBPalpha, and PPARgamma during adipogenesis. Biochem Biophys Res Commun 2004;319:235-239. 